\title{
PRINCIPIOS DEL LENGUAJE Y EDUCACIÓN
}

Alfonso Cárdenas Páez

\section{Introducción}

Roland Barthes (1971), al defender los principios de la nueva crítica y referirse a la libertad simbólica, estableció que "la sociedad clásica por lo común se ha acomodado muy mal a ella: la ha ignorado, o, como en sus supervivencias actuales, censurado; la historia de la libertad de los símbolos es a menudo violenta, y naturalmente aquí tiene igualmente su sentido: no se censuran impunemente los símbolos".

Este planteamiento, apenas uno de los síntomas de la crisis del lenguaje, es una de las manifestaciones de la época actual, atravesada por una enfermedad profunda en que las imágenes de la objetividad, la verdad, la autoridad y la transparencia del lenguaje han dado paso a la crítica y a la interpretación del sentido en todas sus manifestaciones.

Si bien la visión contemporánea no arrastra la censura, aún se oyen voces discordantes para las cuales el lenguaje no es más que un instrumento cuyo papel cognitivo, basado en las habilidades, es el de ser medio unívoco de representación o, en contraposición, un sis tema destinado a la libre interpretación, ambas posiciones extremas, herederas de un dogmatismo cuasi infalible o de un eclecticismo incapaz de reconocer o defender posición ideológica alguna.

La situación descrita ha generado un auge de los lenguajes; de eso es claro testimonio la evolución permanente de las ciencias respectivas que, en su continua búsqueda, han pasado de la consciencia de la lengua a la del lenguaje como síntesis de un fenómeno semiótico-discursivo que, dentro de un marco interdisciplinario, recubre los problemas del sentido en el campo de las ciencias sociales y humanas.

Esta transformación, no exenta de dificultades e incomprensiones, consiste en asumir, por diferentes vías, el conocimiento en la variedad de sus fuentes y de las racionalidades humanas y supone la utilización múltiple del lenguaje de acuerdo con sus funciones pragmáticas; pero no solo eso. Es, además, la aceptación de la pluralidad de los discursos sociales y, des de el punto de vista pedagógico, la mirada del conocimiento en sus dimensiones lógica e imaginaria, así como del comportamiento interactivo, sostenido en actitudes y valores.

Este capítulo ofrece, con fundamento en la investigación adelanta en la Universidad Pedagógica Nacional, ${ }^{*}$ un análisis de las ofertas del Ministerio de

\footnotetext{
* Ccatedrático de la Universidad Javeriana y profesor detiempo completo de la Universidad Pedagógica Nacional. 
Educación Nacional (MEN) en su proyección en el panorama educativo nacional e insinúa otros as pectos pertinentes a las demandas actuales en torno a la docencia del lenguaje.

\section{LAS PROPUESTAS DEL MEN}

En 1984, el Ministerio de Educación Nacional estableció la Renovación Curricular que, en lo relativo al lenguaje, dio paso al Enfoque Semánticocomunicativo (ESC-MEN); este consistía en un conjunto de estrategias teóricoprácticas, destinadas a la enseñanza del español y la literatura. Su fundamento teórico era la relación dialéctica entre lenguaje-pensamiento-realidad y su meta el perfeccionamiento de las habilidades comunicativas: hablar, escuchar, escribir y leer. ${ }^{1}$

Si, por un lado, las habilidades definían el rumbo metodológico y constituían el centro de atención del enfoque comunicativo, por el otro, la relación lenguajepensamiento-realidad precisaba el marco semántico, factores que, al constituirse en nódulos centrales, decidían la estructura teórico-práctica de la propuesta.

Esta plataforma se sostenía en un esquema donde la lengua española era instrumento de pensamiento y de conocimiento; como objeto de conocimiento se ceñía a las tradicionales ciencias lingüísticas, mientras que como "ins trumento de comunicación y de expresión conscientes" servía a los usos cotidiano, científico y literario. Cada nivel era mediado por el análisis y la creación literaria, la teoría literaria y la semiología, más la orientación temática sobre las cuatro habilidades, cuadro que resumía lo que se debía saber de la lengua y de la literatura.

El sus trato semántico se distribuía teóricamente en tres niveles de semantización: conceptual, lógico e ideológico, y su estribo era la estrecha relación entre categorías lógicas y gramaticales; por su parte, el componente comunicativo hacía énfasis en la expresión oral, la lectura y la composición escrita con base en estrategias bien conocidas. En general, el cuadro de contenidos se ordenaba según criterios metalingüís ticos, metodológicos y de teoría literaria.

Sin embargo, esta propuesta no dio los frutos esperados, durante los años subsiguientes; a las inconsistencias y a su escaso desarrollo teórico, se sumó el énfas is en la corrección 1 como factor normativo y preponderante en la formación integral. A estas fallas de dis eño, se agregaron otras de orden administrativo; el MEN poco a poco se desentendió del enfoque, los Centros Experimentales Piloto (CEP), encargados por ley de adelantar la labor en sus respectivas regiones,

\footnotetext{
** La investigación anunciada - DEL-124-98 - se titula "Un marco semiótico-discursivo para la docencia del español”, patrocinada por UPN-CIUP.

${ }^{1}$ Los fundamentos de la Renovación Curricularpertinentes al enfoque aludido se pueden consultar en MEN (1984).

Marcos generales de los programas curriculares, Bogotá, MEN.

${ }^{2}$ Esta versión casi textual se lee en la metodología del enfoque propuesta por los marcos, así como en las ediciones posteriores de Case.
} 
poco contribuyeron a su multiplicación y todo quedó en manos de editores que, con mayor o menor acierto, interpretaron el modelo, dando lugar a la proliferación de textos y a no menor confusión en los docentes del español.

Además, los maestros, directos responsables de su desarrollo y ejecución, según se desprende del análisis de 160 encuestas aplicadas a maestros de Educación Básica, no tuvieron la asesoría adecuada para tal fin. Si bien la mayoría acepta conocer y aplicar el enfoque del MEN en un $73 \%$, le asigna a los textos escolares un papel preponderante en la multiplicación con un $48 \%$, porcentaje que dobla los cursos de escalafón con un $28 \%$, quedando reducido el papel del MEN a un $11 \%$ y el del CEP a un $9 \%$. Estos datos son consistentes con el papel destacado de la teoría lingüística en la docencia del español con un $67 \%$ y con la metodología en donde prevalece la exposición oral con un $87 \%$, muy ceñida al uso del texto-guía con un $84 \% .3$

No es difícil inferir, pues, las tendencias memoris ta y directiva de la docencia que, basada en la enseñanza teórica, en la vigencia del maestro y en el predominio del texto escolar, reduce la experiencia del estudiante a su mínima expresión, otorgándole la mayoría de créditos al texto como herramienta metodológica, no sólo en el aprendizaje del estudiante sino como manual de (in-) formación del docente.

Desde aquí, cabe formular la sospecha acerca del proceso de flexibilización curricular4 y de la creación del bibliobanco, modificaciones posteriores al enfoque, al igual que lo son la Ley 115, el Plan Decenal de Educación, el Proyecto Educativo Institucional (PEI) y los Lineamientos Curriculares de Lengua Castellana, este último de reciente publicación.

\section{Reflexiones acerca de la Ley 115 y sus aplicaciones}

La Ley 115, descontando las observaciones de Bustamante (1994-95), en los literales b, c de los artículos 20 y 21, establece respectivamente los objetivos generales yespecíficos de la Educación Básica. Alí se insiste en "Desarrollar las habilidades comunicativas para leer, comprender, escribir, escuchar, hablar y expresarse correctamente". Esta prescripción difiere poco de la sugerida por las reformas de 1974 y de 1984. Lo que hace es insistir en y confundir la comprensión y la expresión correcta - claro está -, como si tales fenómenos

\footnotetext{
3 Estos datos, recabados entre los años 1995 y 1996 cuando ya se aplicaba la Ley General de Educación, son consistentes con los procedentes de la región centro-nor-oriental del país. Un análisis detallado del Enfoque Semántico-comunicativo se encuentra en Romero V., Rita y otros (1986), CARDENAS, Alfonso y otros, (1986-92a,b) y CARDENAS, Alfonso (1995).

4 La puesta en marcha de la descentralización y de la flexibización curricular se fundamentó en la Ley 24 de 1988, pero de acuerdo con datos a escala nacional, tal responsabilidad asignada a los CEPs no se cumplió a cabalidad, sobre todo en lo pertinente a la renovación curricular y a su implementación. Esto introduce serias dudas acerca de la responsabilidad con que se pueda asumir la actual descentralización educativa si el gobierno nacional no hace un es fuerzo de capacitación del grupo docente, pues la renovación académica no se ha dado aún en las Universidades encargadas de formar a los docentes.
} 
fueran extraños a las habilidades, y la expresión, función por demás ambigua a juzgar por los literales c, d del artículo 21, debiera nomativamente ser correcta so pena de no ser eficaz. Esta confusión no extraña tampoco en los logros educativos; ante todo, porque aún no se han dado los desarrollos necesarios al conjunto de com petencias que conforman el lenguaje.

De contera, al hacer énfasis en las habilidades reduce la lengua a su función instrumental, resalta el desconocimiento de las circunstancias específicas de uso y confunde las habilidades con los procesos de producción e interpretación de sentido y con las funciones del lenguaje. Además, introduce una contradicción manifiesta entre la búsqueda de la identidad propuesta por el PEI y la carencia de "tradición lingüística propia" de los hablantes del castellano como lengua materna.

Estos factores inducen a pensar que, en relación con el lenguaje, la Ley 115 no tiene los alcances que se le atribuyen en algunos medios; de esas limitaciones surgen los inconvenientes de la oferta mayor de la citada Ley: el Proyecto Educativo Institucional (PEI). ${ }^{5}$

El PEI, en síntesis, intenta varias cosas a la vez: romper las fronteras de la escuela, propiciar la participación de y comprometer a la comunidad educativa en la descentralización y en la contextualización del proceso curricular, y favorecer la autonomía, con miras a la formación integral de los educandos, a la construcción de la identidad, a la educación analítica, crítica e investigativa y a la solución de los problemas regionales.

Estas metas, plausibles y deseables por los demás, afrontan en su cumplimiento diversas dificultades; aunque algunas de ellas han sido analizadas por Bustamante (1995), Alvarez Gallego (1995) y Perafán (1995), nuestro interés se centra en la propuesta de Ordóñez Pachón (1995) y ARCOD (1994), documentos de presentación y reflexión donde se revelan las incons istencias entre la Ley 115 y el PEl.

De acuerdo con Ordóñez, el PEI es un proyecto inscrito en el contexto de la educación como producción cultural ${ }^{6}$ o de producción e intercambio de símbolos y signos (intercambio de sentido) que, mediado por el lenguaje, pone en crisis la verdad, gracias a la interacción humana en que se construyen integralmente el conocimiento y el comportamiento específicos de la persona humana.

En efecto, la tesis de Ordóñez es consistente con la crítica del lenguaje prevista por Barthes al principio de este trabajo, así como con una lingüística del lenguaje y con la base semiótica del mismo que ponen en entredicho el logocentrismo y la

\footnotetext{
${ }^{5}$ Como se verá en el Capítulo 7, el PEI es uno de los elementos fundamentales de la integración curricular y de la pedagogía reconstructiva e interactiva.

${ }^{6}$ Esta propuesta guard a relación con la de Avila Penagos (1994) para quien "la cultura es el campo de trabajo de la educación. La educación es un trabajo sobre la cultura". (p.37) El complemento de la propuesta se da en el én fasis que el autor confiere a las disciplinas semiológicas en la Educación Básica, en torno a lo que el autor llama adquisición de una cultura básica.
} 
representación única y caracterizan el momento histórico, en que, frente al avance científico y tecnológico y a la construcción de nuevos valores y actitudes que sostengan la toma de decisiones y el logro de consensos, es imprescindible un enfoque educativo que, centrado en el lenguaje, asuma el lugar que le corresponde en el proceso educativo en todas sus dimensiones y consecuencias.

Por su parte el MEN, en el documento "Reflexiones sobre los proyectos educativos institucionales (ARCOD, 1994, 67), acorde con las tesis de que "Toda actividad pedagógica se basa en algún modelo de comunicación", al reconocer el corte directivista de la educación anterior que exige la pasividad, el silencio y el respeto a normas por parte del estudiante, propone la participación de éste en la construcción de conocimiento y de saberes y la acción pedagógica en favor de la "capacidad del estudiante para participar en la interpretación y en la interpretación de saberes".

Sin embargo, cabe sospechar que la Ley 115, al insistir en el substrato conductista de las habilidades, en términos de hábitos y de resultados, no favorece en nada el desarrollo de los PEls. A falta de explicitud, cabe preguntar: ¿Cuáles son los hábitos que se persiguen: sensoriales, motores, senso-motores o intelectuales? Si la visión lingüística del castellano corresponde a la lengua como sistema e instrumento, ¿Cómo favorecer el conocimiento y la interacción a partir de la concepción del lenguaje como proceso? ¿Cómo contribuir al desarrollo de las competencias cognoscitiva, interactiva, semiótica y discursiva de los estudiantes? ¿Cómo propiciar el cambio en los maestros de la visión sistemática e instrumental a la visión del lenguaje como proceso semiótico-discursivo, implicado en el pensamiento y en la interacción?.

\subsection{Acerca de los lineamientos curriculares ${ }^{7}$}

A pesar de que los lineamientos curriculares logran avances desde la lingüística textual y la semiótica, persisten en ellos las tendencias, ya analizadas, a sumar elementos, a centrar el trabajo didáctico en las habilidades y a obviar la coherencia del marco que se propone a partir de una concepción de la lengua.

Aunque se distingue entre lo semiótico y lo significativo, no es clara la concepción de lo semiótico, como tampoco lo son los criterios que motivaron la decisión de someter lo comunicativo a lo significativo, ${ }^{8}$ más allá de la referencia bibliográfica. Desde este punto de vista, el enfoque deja de ser semánticocomunicativo para convertirse en semiótico-semántico contrariando, eso sí, un

\footnotetext{
${ }^{7}$ MEN, Lengua Castellana - Lineamientos curriculares, Bogotá, MEN, 1998.

${ }^{8}$ En nuestro sentir, esta desatención a la función expresiva y, de contera, a lo analógico, así como a los valores y a la dimensión ética que se desprende de la cosmovisión impide que se pueda construiruna pedagogía de la literatura. Aunque este tema es objeto de otro trabajo, algunas notas con respecto al tema apuntan a distinguir entre estéticas de la sensibilidad y de la forma; a diferenciar las posiciones críticas frente a la literatura, desde los contextos o desde el lenguaje; a concebir la literatura como discurso plurisignificativo. Ahora bien, la literatura es un asunto de conocimiento analógico en que se tocan sensibilidad e imaginación y un fenómeno semiodiscursivo específico, aunque no exclusivo, de índole icónicay simbólica.
} 
poco la tendencia generalizada a ver lo semiótico en relación con los medios extralingüísticos, pero no sacando las debidas consecuencias ${ }^{9}$ con respecto al lenguaje verbal, donde se manifiesta la triple codificación denotativa, connotativa y metasemiótica con todos sus atributos: diversidad de signos, intertextos y códigos semióticos, textos y discursos que enriquecen el sentido.

Por eso, aún se privilegia la lingüística teórica sobre una semiolingüística aplicada; desde luego, hay un repunte renovado de lo metalingüístico, ahora desde lo textual que, en nuestra opinión, continúa la línea del ESC-MEN, identificada tanto en las encuestas y diarios de campo de la investigación mencionada y, también, analizada por varios expertos en el tema.

De igual forma, se insiste en las habilidades pero desde una generalidad que contrasta con la precisión de los indicadores de logro y, más extraña aún, cuando la competencias, como núcleo de atención pedagógica, facilita establecer la relación logro/indicador con su correlato: la actuación. De igual manera, tampoco se proveen las pautas para afianzarlas en el contexto cultural que enmarca la práctica educativa.

De tomarse las competencias como principio del aprendizaje del conocimiento y del comportamiento, a través del lenguaje, es posible comprenderlas como conjuntos de habilidades y aptitudes, reconociéndoles un nivel operacional accional, formal y figurativo, así como medios de control metacognitivo y posicionarlas dentro de la clase y la escuela como comunidades de habla. En adición a esto, las competencias se centran en la lengua y no en el lenguaje; al parecer, no se reconocen las competencias semióticas en el lenguaje verbal que ofrece todas las dimensiones del sentido por su capacidad multicodificadora y multifuncional.

Sumado a estos perfiles, el planteamiento sigue siendo demasiado lógico; aunque por momentos se reconoce la conformación del texto a través de una red de enunciados, en otros, lo que se privilegia es el plano proposicional, cuando no lo oracional ( Cf. microestructura textual); este triple juego es nocivo para la comprensión de los fenómenos del lenguaje, pues funde enfoques y fenómenos distintos y no distingue, por ejemplo, las estructuras de la información gramatical, temática, enmarcada -, cam pos del lenguaje donde se da la realización gramatical de la oración, frente al contenido informativo y al marco de inserción de la información. Bien sabemos los problemas que tal confusión suscita, al tenor de la tesis de Lyons (1997) acerca de la oración como unidad abstracta de enunciados posibles y la necesidad de diferenciar entre el contenido proposicional y las condiciones de verdad del significado oracional.

Además, se relaciona la coherencia con y se reduce al 'orden lógico' - término por demás poco claro pues no sabemos si se refiere a operaciones, a relaciones, a formas o a reglas - con lo cual se minimiza lo semántico y, de paso, se excluye

\footnotetext{
${ }^{9}$ Nos referimos, por ejemplo, a las que se derivan de las reflexiones críticas y hermenéuticas de Habermas, propuestas en el documento "Reflexiones sobrelos Proyectos Educativos Institucionales”, (ARCOD, 1994). 
lo pragmático como factor integrante, junto con el anterior, de este componente de la unidad textual.

Un somero análisis del cuadro "Niveles de anális is y producción de textos", nos permite comprender algunos de los planteamientos hechos. En él, aparecen dos funciones distintas del área fundidas en el mismo plano, cuando deberían distinguirse pues, de lo contrario, se concede privilegio a lo metalingüístico. Tampoco consideramos afortunada la división entre lo intratextual, lo intertextual y lo extratextual; ${ }^{10}$ otra cosa es si se recuperan categorías como textualidad, subtextualidad, intertextualidad y contextualidad como niveles referidos al mismo asunto: el texto en su papel discursivo.

Por ejemplo, allí se habla de 'esquema lógico' de la organización textual : apertura, conflicto y cierre que, en criterio nuestro, es un factor de la dinámica textual. De igual modo, se localiza la ideología en el plano extratextual; una cosa es que la ideología tenga manifestaciones ajenas al texto y otra cosa reducirla solo al contexto. Aquí vale la pena traer a colación, sin comentario, a Voloshinov(Bajtín) (1992, 31-32-33) quien afirma: "Todo producto ideológico posee una significación: representa, reproduce, sustituye algo que se encuentra fuera de él, esto es aparece como signo. Donde no hay signo no hay ideología ....". "Todo lo ideológico posee una significación sígnica....". “...el carácter sígnico es la deteminación general de todos lo fenómenos ideológicos”. (El subrayado es del autor)

Frente a la insuficiencia de la lingüística, es necesario apuntalar la pedagogía del lenguaje en la semiótica y no en la lingüística; no obstante el precedente histórico y epistemológico de esta, aquella ofrece mejores perspectivas y un marco general, amplio y rico en signos, códigos, textos, intertextos, subtextos y contextos. En nuestro sentir, pensar la lengua que se enseña y se aprende desde modelos teóricos es hacer de la pedagogía de la lengua un problema puramente metalingüís tico. ${ }^{11}$

De igual modo, hay confusión entre lo que son la funciones, los principios, los contextos y los procesos pedagógicos del lenguaje; por eso, consideramos necesario distinguir estas categorías y, a partir de allí, definir los principios de una semiolingüística aplicada a la docencia de la lengua y de la literatura, de manera que se precise el tipo de pedagogía - reflexión de la que adolecen los lineamientos - que conviene a la naturaleza semiodiscursiva y a la función sociocognitiva del lenguaje.

Teniendo en cuenta estos interrogantes, es difícil comprender la manera se sostienen dos tesis contrarias y desfasadas, en el interior de la noma que define

\footnotetext{
${ }^{10}$ Por ejemplo, esta tesis no es coherente con el reconocimiento que el documento en cuestión hace de la presencia del lector, implicado en el texto.

Concebir la pedagogía del lenguaje desde esta perspectiva, implica no atenerse a los principios que definen la educación como una práctica social y, por supuesto, cultural e ideológica. Además, supone excluir de la educación la problemática del sentido.
} 
los principios generales de la educación colombiana, lo cual no niega la necesidad de darle coherencia a las nomas y de desarrollarlas de acuerdo con otros principios y herramientas teóricas.

\section{EDUCAR EN EL LENGUAJE: UNA ALTERNATIVA}

Desde la concepción planteada, el lenguaje es un fenómeno de producción e interpretación de mensajes, realizado gracias al ejercicio de diversas competencias, cuyo papel representativo es múltiple frente al mundo, en cuanto destinado a satisfacer numerosas funciones discursivas. Este punto de vista supone una pedagogía que, superando los linderos de la lingüística de la lengua, le reconozca al hombre una capacidad semiótica general, dé vía libre a la autoformación a través del desarrollo de conocimientos, aptitudes, actitudes y valores y permita la contextualización discursiva de las funciones básicas del lenguaje: cognoscitiva, comunicativa y expresiva.

Sin desconocer su naturaleza sistemática, la visión del lenguaje esbozada permite inscribir el sentido en la cultura que, en sus dimensiones imaginaria, valorativa, institucional e industrial, está poblada de fenómenos semióticos simbólicos, codificados, textuales y discursivos - que rigen el conocimiento y el comportamiento humanos.

Por tanto, desde la semiótica, el conocimiento es un proceso conformado por dos campos fundamentales: el lógico y el imaginario (Oñativia, 1978). El primero es el dominio de la razón, de los sistemas y de las operaciones lógicas; es el campo de las diferencias, de los conceptos y de las categorías.

El segundo se conforma alrededor de diversos ámbitos: mítico, mágico, lúdico, onírico, fantástico, afectivo, sensorial, etc.; su dinamismo está en la analogía y su unidad básica es el símbolo; su procedimiento es el sincretismo y su origen está en la intuición.

En otro plano, la semiótica incorpora múltiples formas sígnicas - signos, señales, indicios, iconos, símbolos, etc. y códigos semióticos y del sentido; pero, ante todo, supone la pluralidad de la representación que, en sus variadas formas, mina la transparencia y univocidad del signo, impidiendo que la significación se reduzca a la referencia.

Con respecto a lo anterior, la acción pedagógica debe poner en entredicho las pretensiones de verdad única, de objetividad y de autoridad que han sido patrones de la educación tradicional y permitir la discusión, la argumentación y la interpretación como actitudes antilogocéntricas (Eco, 1974), sin olvidar el pensamiento creativo tanto en su dimensión convergente como divergente (Desrosiers, 1993).

De igual manera, al orientarse el proceso educativo en torno a esta concepción del lenguaje, a nadie se le oculta la necesidad de comprender el conocimiento según formas de la racionalidad, hoy reconocidas (Habemas, 1989), tanto en su 
dimensión cognitiva como ética y estética. Sobre esta base se puede promover la persona integral y, en torno a ella, el mutuo entendimiento, el compartir saberes, la intención de que se crea en las máximas cooperativas de la comunicación, de que se consientan los mismos presupuestos; en fin, de que en la interacción se sostengan las funciones del lenguaje.

En contra de la insistencia de la escuela en el carácter constatativo y directivo de sus discursos, esto es lo deseable; ya no basta decir verdades o prescribir acciones, prestando poca atención al diálogo, al análisis, a la interpretación, al pensamiento creativo y a la crítica. Sin embargo, no se trata de enseñar teóricamente los principios cognoscitivos y pragmáticos del lenguaje; se debe abrir el espacio escolar a su realización, desde una pedagogía de la personalización y de la contextualización.

Estos planteamientos inducen, por otro lado, a pensar que no basta la gramática; por lo mismo, la docencia del lenguaje debe pasar del estudio de la oración, al texto y al contexto, es decir, al discurso (Dijk, 1980), a la estructura temática, a las operaciones y procedimientos discursivos, a las modalidades y puntos de vista. A esto se suman las características y esquemas textuales, la intertextualidad y la capacidad de todo texto de generar antidiscursos para propiciar la polémica y la producción de otros que deconstruyen los que les sirven de base.

Tampoco bastará, entonces, la competencia lingüística; según se concluye de las tesis de varios autores ${ }^{12}$, la competencia debe ser semiótica, cognoscitiva y comunicativa, no solo en lo que respecta al lenguaje como objeto de estudio sino en lo pertinente a sus procesos a los cuales contribuye decisivamente: pensamiento, interacción, lectura y escritura. ${ }^{13}$

Sin embargo, no son estas las únicas consideraciones que pueden hacerse al respecto; la naturaleza semiodiscursiva del lenguaje se confoma en tomo a los subprocesos de semiotización, semantización y comunicación. La primera es un proceso cultural propio de la formación cosmovisionaria ${ }^{14} \mathrm{y}$, por tanto, de la diversidad de la significación. Gracias a ella, el hombre introduce la base de comprensión del mundo complejo, decidiendo con eso la imposibilidad de conocimiento extrasemiótico. ${ }^{15}$

La semantización concreta en texto las formas de la semiotización, ordenándolas en dos niveles: estructural y no estructural, a los cuales, de paso,

\footnotetext{
${ }^{12}$ Entre los autores que amplían a otros campos el principio de competencia podemos citar a Hymes (1984), Eco (1981), Vigner (1982), Habermas (1989), Péry-Woodley (1993), Avila Penagos (1994), Mockus y otros (1995). Todos ellos utilizan la categoría para referirse a los procesos de conocimiento, comunicación, lectura, escritura o educación.

13 La orientación del proceso educativo hacia estos núcleos de enseñanza es una de las concepciones que se desprende de la investigación del autor en tomo a ladocencia del español.

La formación cosmovisionaria, como formación histórica, implica sostener un principio de totalidad y un sentido de la Yida relacionados con las relaciones entre el hombre y su subjetividad, el hombre y el mundo y el hombre y lasociedad.

Uno de los analistas en reflexionar acerca de este proceso, desde la perspectiva textual, extratextual y metatextual es Mignolo (1978); sin embargo, nuestro punto de vista se basa en las orientaciones de Greimas $(1971,1973,1976)$ quien distingue claramente dos niveles de sentido: interoceptivo y exteroceptivo o sémico y semántico.
} 
podríamos atribuir la estructura temática y la cohesión respectivamente. Estas propiedades inciden, en gran parte, en la necesidad de interpretar con cierta univocidad los textos. (Eco, 1981)

Por su parte, la comunicación construye pragmáticamente la relación del texto con la situación y con los usuarios; sus elementos son modalidades, puntos de vista, propósitos, nomas de interacción y de interpretación, estilos, registros, géneros y juegos de lenguaje; en síntesis, arquitectura del lenguaje. (Coseriu, 1977)

El otro campo, el desarrollo de la interacción, deberá obedecer a la consciencia de que ninguna acción humana se realiza al margen del lenguaje; dicha consciencia debe orientarse a la fomación de actitudes y valores hacia el mundo, hacia la sociedad y hacia el yo. Esto muy a pesar de la variedad de estudios en lo tocante al tema des de la perspectiva de la pragmática. (Kerbrat-Orecchioni, 1990 y 1992)

Por un lado, la formación de actitudes se ocupa de la capacidad para adoptar posiciones y tomar decisiones frente a situaciones vitales en las que se desempeña el hombre; esta capacidad entraña una carga semiótica que va desde la diferencia sexual entre hombre y mujer hasta las capas más profundas del pensamiento lógico. Ser amanerado, aceptar que "los hombres no deben llorar", utilizar cierto atuendo, "tener más de dos dedos de frente", escoger una carrera universitaria, hacer la tarea, leer con deteminado propósito, resolver un problema matemático, etc. son asuntos cuyo interés e importancia dependen de actitudes. Posiciones, decisiones, dichos y expresiones son formas de manifestar actitudes, pero estas no se dan al margen de modalidades, de propósitos, de puntos de vista.

Por el otro lado, la fomación de valores apunta a la instauración del hombre como sujeto social que experimenta el 'mundo' y lo vivencia, interesándose en él en cuanto, frente a los demás, descubre el sentido de los bienes que puedan favorecer la vigencia de la vida humana. Así como las actitudes, los valores no son extraños a la noma, a la ley, a la costumbre; de manera idéntica que el lenguaje, tampoco operan al margen de una situación.

Así, pues, valores y lenguajes son prácticas significantes íntimamente relacionadas pues tocan con las facetas cognoscitivas, ética y estética del ser humano. En consecuencia, son decisivos en la manera como el ser humano actúa, se comporta, se expresa, informa e interpreta.

Estos principios, según los cuales la comunicación y el conocimiento humanos están influidos por las prácticas semiodiscursivas pueden contribuir al mejoramiento del proceso educativo. Por tanto, sus consecuencias pedagógicas no se hacen esperar. 


\section{CONSECUENCIAS PEDAGÓGICAS}

Sobre la propuesta anterior, es posible plantear, por el momento, varias consecuencias metodológicas relacionadas con las competencias, el desarrollo del conocimiento, el papel de los metalenguajes, la necesidad de superar el esquema de habilidades y de incorporar la personalización educativa y la contextualización curricular.

Liberando la propuesta chomskiana de su base innata, la docencia del lenguaje debe basarse en principios semióticos y discursivos y desarrollar las competencias en los planos cognitivo, metacognitivo e interactivo. Esto favorece la propuesta de Mockus y otros (1995) acerca de la pedagogía como ciencia reconstructiva que, al jugar entre el saber-cómo y el saber qué, hace posible la competencia comunicativa atenida a las pretensiones de validez, específicas del desempeño discursivo de las personas.

Si se acepta que la competencia comunicativa recubre los campos gramatical, sociolinguístico, discursivo y estratégico (Canale, cit. por Coulthard, 1993, 147), se puede orientar al estudiante en varios campos a la vez: descubrimiento de la naturaleza de los sistemas semióticos, análisis de ambigüedades y uso de modalidades y puntos de vista, etc., todos ellos factores necesarios para la producción e interpretación del sentido, en el campo verbal y no verbal.

Además, se le puede dirigir en el manejo de unidades, códigos y estructuras semióticas, llevándolo a la reflexión sobre la producción de textos adecuados a contextos específicos, acerca de las formas de la repres entación - generalización, abstracción, indicación, identificación, analogía, semejanza, etc.-, y de la estructura temática y global de los textos.

De alguna manera, cualquier pers ona es competente en el lenguaje; acrecentar esa competencia y alcanzar mejores niveles de consciencia acerca del uso eficaz del lenguaje es papel del docente, a quien corresponde adoptar estrategias para que el alumno lo descubra y proyecte en los campos de la vida cotidiana y lo ponga al servicio del estudio.

Otra de las consecuencias se relaciona con el conocimiento en sus niveles lógico e imaginario. Es ya atávica la tendencia educativa a destacar los aspectos lógicos del conocimiento, en favor del memorismo. Puesto que siempre se ha hecho énfasis en habilidades, en principio se debe apuntalar el pensamiento convergente considerando la conceptualización, categorización, sistematización y operacionalización de contenidos significativos y sus relaciones lógicas, con vista a que la psicosemiótica explica el aprendizaje lingü ístico desde la pragmática y no desde la fonética.

Para lograrlo, se debe recurrir a los marcos de conocimiento del estudiante y a los presupuestos desde los cuales comprende el mundo e interactúa socialmente para someterlos a discusión e intercambio de opiniones que, fundamentadas y 
argumentadas, producirán el 'conflicto cognitivo' (Carretero, 1994) sobre los distintos saberes acerca de un determinado tema.

Por su parte, el pensamiento divergente deberá consolidarse atendiendo a principios analógicos y recurriendo a medios y procedimientos expresivos, así como a disposiciones y actitudes de los participantes en los niveles intra e intersubjetivo. Además, se habrá de recuperar la sensibilidad, la imaginación, el juego y la creatividad tanto lógica como analógica, con miras a formar la unidad indisoluble del ser humano.

Desde la perspectiva planteada, se llega otra decisión metodológica; la concepción interactiva será base para construir la personalidad del estudiante en sus niveles psíquico y social, integrando en ella lo cognoscitivo, lo conductual y lo estético. Así, los intereses, las aspiraciones, las convicciones, las posiciones, los puntos de vista, la cosmovisión, la idea de sí mismo, la actitud frente a los demás, la valoración de bienes, las personas, servicios, etc. tendrán que ver de manera directa con el lenguaje como conjunto de códigos que regulan el sentido del mundo y de la cultura.

Toca, entonces, al maestro estimular la actitud de comprender y valorar el mundo y la cultura; de comprender el sentido de conceptos, nociones, creencias, hechos y fenómenos, la actividad y la interacción humanas. De esta forma, la necesidad de mejorar, de conocerse y autoafirmarse, la satisfacción de necesidades, el deseo de alcanzar metas e ideales personales y sociales, la decisión de seguir ciertos modelos o de servirse de objetos, de buscar la verdad y el placer pueden ser considerados y atendidos des de le lenguaje.

Como se ve, ninguno de los dos grandes sectores de crecimiento personal del estudiante - el conocimiento y la interacción - ha de reducirse a habilidades; las razones de esto se explican en Bruner (1991); este autor considera que las habilidades se han de poner en contexto y no deben ser el único propósito educativo; asimismo, piensa que un marco discursivo - como el propuesto asegura en gran medida el tratamiento de los valores; entre otras cosas porque adoptar puntos de vista y modalidades, al igual que expresar propósitos comunicativos, supone tomar posturas frente al mundo, la sociedad y las personas.

Por eso, el maestro no puede reducir su acción a la prédica teórica del lenguaje, mucho menos concentrarla en los as pectos sis temáticos; al contrario, debe bus car la participación del estudiante de manera que la voz imperativa ceda al diálogo en donde se razone, se opine, se argumente, se proponga, se comente, se analice, se interprete y se critique diversas posiciones para asumir otras que siem pre serán respetables pero jamás únicas definitivas.

En atención a lo dicho, ¿se deben abandonar los metalenguajes? Como es obvio, existe resistencia por parte de maestros y alumnos a los metalenguajes. A pesar de ella, creemos que es necesario asumirlos como soporte metacognitivo 
para que cumplan su papel de consciencia y de control de los procesos y sirvan para

Predecir las consecuencias de una acción o acontecimiento, comprobar los resultados de nuestras propias acciones (¿han sido eficaces?), vigilar la actividad que estamos realizando (¿progreso satisfactoriamente?), comprobar la realidad (¿tiene esto algún sentido?) y otros muchos comportamientos que apuntan a coordinar y controlar los intentos deliberados de aprender a resolver problemas. (Brown y De Loache cit. por Schwebel, 1985).

La consecuencia de esta tesis consiste en conferille el lugar adecuado a las aptitudes en el proceso educativo; a diferencia de la concepción tradicional, para nosotros, la aptitud es la capacidad para seleccionar la operación o la estrategia adecuada a cada actividad, lo que requiere un alto grado de consciencia; ese sería un objetivo metacognitivo básico de todo maestro.

Esta precisión es fundamental si se piensa en lo que Dickinson (1991), citando a Flavell, establece al respecto: el conocimiento, además de saber e información, comporta objetivos, estrategias y acciones que son propias del aprendizaje deliberado.

A lo dicho, se suman otros factores muy importantes que sólo enumeraremos; el primero se refiere a la obligatoria reducción de los contenidos pues no se trata de memorizar información sino de hacena operativa al servicio de problemas de aprendizaje en el uso transaccional del lenguaje. Otro tiene que ver, como ya se mencionó, con el favorecimiento cognoscitivo e interactivo del pensamiento, el diálogo, la escritura y la lectura en la docencia del lenguaje, así como las necesarias personalización y contextualización del proceso de discursivo. De estas dos últimas, la personalización se relaciona íntimamente con la competencia, mientras que la contextualización se asocia con el discurso.

Tomando en cuenta el proceso de lenguaje, en su naturaleza, en sus consecuencias pedagógicas y en el juego de sus múltiples niveles y dimensiones, creemos que el maestro recursivo y creativo puede - previa la ampliación de estos principios -, realizar una docencia de calidad basada en una concepción cognitiva e interactiva y en el control consciente de las diversas actividades semiodis cursivas que le son propias.

La calidad de esa docencia depende de la adopción de un enfoque fenomenológico, de acuerdo con el cual, frente a la construcción significativa del aprendizaje desde el mundo cotidiano compartido, se establezca un diálogo en torno al sentido de la cosmovisión que lejos de comprometerse con una verdad específica, la busque en los principios, y entienda que quien se educa es una persona que, en calidad de tal, es sujeto interesado en el conocimiento, con su carga de sentimientos y de condiciones surgidas del contexto de sus vivencias. 
Debido a lo anterior, el docente de lenguaje debe ser el mejor de cada institución educativa; no en cuanto al saber, sino a la mayor comprensión de los fenómenos de sentido que se producen en torno al proceso pedagógico, máxime cuando su área media en la vida personal y social del aprendizy en el estudio de las demás asignaturas, convirtiéndose, además, en objeto de una ciencia en particular, tres funciones que la distinguen de las demás y le otorgan especial relieve en el campo educativo.

Pero, lograrlo exige un cambio radical de los maestros, quienes deben ser los primeros en asimilar el nuevo marco. Cambiando la concepción del lenguaje y creando consciencia de ese cambio así como de las posibilidades de aplicación para el mejoramiento de la docencia, se podrán superar los altos índices de exposición, de uso del manual escolar, de teorización, de memorismo, de representación unívoca, de normativismo y directivismo, factores que caracterizan, hasta ahora, y dificultan la ens eñanza de la lengua.

\section{BIBLIOGRAFÍA}

AL VAREZ G., Alejandro, (1995). "Proyecto Educativo Institucional: respuesta de la escuela a una nueva época". En Pretextos Pedagógicos, No. 2, pp.27-35.

ARCOD, (1994). Aspectos Pedagógicos y organizativos de la educación formal, Bogotá, Ediciones Pedagógicas.

AVILA P., Rafael, (1994). La educación y el proyecto de la modemidad, Bogotá, Antropos Ltda.

BARTHES, Roland, (1971). Verdad y crítica, México, Siglo XXI.

BRUNER, Jerome, (1991). Actos de significado, Madrid, Alianza.

BUSTAMANTE, Guillermo, (1994). "El lenguaje en la Ley General de Educación". En La Palabra, No.3, pp. 47-54.

, (1995). "Acontecimientos relacionados con la aparición del Proyecto Educativo Institucional”. En Pretextos Pedagógicos, No.1, pp.37-44. CARDENAS P., Alfonso, (1995). "Un marco semiótico-discursivo para la docencia del español". (Informe de investigación), Bogotá, UPN-CIUP.

CARDENAS P., Alfonso y otros, (1986-92a). Proceso curricular del lenguaje, arte y cultura y educación de primaria, Pamplona, FEADEC.

CARDENAS P., Alfonso y otros, (1986-92b). Proceso curricular de los idiomas, arte, cultura y deportes de secundaria, Pamplona, FEADEC.

COULTHARD, Malcom, (1993). An introduction to Discourse Analys is, New York, Logman.

COUSERIU, Eugenio, (1977). Principios de Semántica Estructural, Madrid, Gredos.

DESROSIERS-SABBATH, R. (1993). L'enseignement et l'hemisfère cérébral droit, Québec, Presses de l'Université de Québec.

DICKINSON, Leslie, (1991). Self-instruction in Language Learning, Cambridge, Cambridge University Press.

DIJK, Teun Van, (1980). Texto y contexto, Madrid, Cátedra. 
ECO, Umberto, (1974). Tratado de semiótica general, Barcelona, Lumen. (1981). Lector in fabula, Barcelona, Lumen.

HABERMAS, Jürgen, (1989). Teoría de la acción comunicativa: complementos y estudios previos, Madrid, Cátedra.

HYMES, Dell, (1984). Vers la compétence de comunication, Paris, Hatier-Credif. KERBRAT-ORECCHIONI, C. (1990-92). Les interactions verbales, Paris, Armand Colin, Tomes I y II.

MIGNOLO, Walter. (1978). Elementos para una teoría del texto literario, Barcelona, Crítica.

GREIMAS, A.J. (1971). Semántica es tructural, Madrid, Gredos. , (1973). En torno al sentido, Barcelona, Fragua. (1976). Sémiotique et Sciences sociales, Paris, Seuil.

MINISTERIO DE EDUCACION NACIONAL, (1984). Marcos generales de los programas curriculares, Bogotá, MEN.

Lineamientos curriculares, Bogotá, MEN.

(1998). Lengua Castellana -

MOCKUS, Antanas y otros, (1995). Las fronteras de la escuela, Bogotá, Magisterio.

OÑATIVIA, Oscar, (1978). Antropología de la conducta, Buenos Aires. Guadalupe.

ORDÓÑEZ P., Carlos, (1995). "Los Proyectos Educativos Institucionales como discursivo educativo". En Pretextos pedagógicos, No.1, pp.11-36.

PERAFAN, Andrés, (1995). "Proyecto Educativo institucional y currículo". En Pretextos Pedagógicos, No.1, pp.45-53.

PERY-WOODLEY, Marie-Paule, (1993). Les écrits dans l'apprentissage, Paris, Hachette.

ROMERO, Rita y Otros, (1986). Conocer, comunicar, actuar. Bogotá, Cepecs. SCHWEBEL, Milton, (1985). "El desarrollo cognitivo". En Pers pectivas, UNESCO, Vol.15, No.2, pp.165-183.

VIGNER, Gérard, (1982). Ecrire: éléments pour une pédagogie de la production écrite, Paris, CLE International.

VOLOSHINOV, N. (BAJTIN) (1992). El marxismo y la filosofía del lenguaje, Madrid, Alianza. 